\title{
The respiratory presentation of severe combined immunodeficiency in two Mennonite children at a tertiary centre highlighting the importance of recognizing this pediatric emergency
}

\author{
Simon Lam $M D^{1}$, Fotini D Kavadas $\mathrm{MD}^{2}$, Seemab Haider $\mathrm{MD}^{3}$, Mary E Noseworthy $\mathrm{MD}^{4}$
}

\begin{abstract}
S Lam, FD Kavadas, S Haider, ME Noseworthy. The respiratory presentation of severe combined immunodeficiency in two Mennonite children at a tertiary centre highlighting the importance of recognizing this pediatric emergency. Can RespirJ 2014;21(1):17-19.

Severe combined immunodeficiency (SCID) is considered to be a pediatric emergency, with respiratory distress being the most common presenting symptom. The authors present two cases of SCID in children $<4$ months of age with respiratory distress at a tertiary care centre due to a recently described homozygous CD3 delta mutation found only in the Mexican Mennonite population. Failure to respond to broad-spectrum antibiotics prompted investigation for possible SCID. Bronchial alveolar lavage fluid from both patients grew Pneumocystis jiroveci, and flow cytometry revealed absent $\mathrm{T}$ cells. The CD3 delta gene is believed to be important in $\mathrm{T}$ cell differentiation and maturation. The present article reminds pediatricians and pediatric respirologists that the key to diagnosing SCID is to have a high index of suspicion if there is poor response to conventional therapies.
\end{abstract}

Key Words: CD3 delta; Infant; Mennonite; Respiratory distress; Severe combined immunodeficiency (SCID)

Learning objectives

- To recognize that a respiratory focus is a common presentation for patients with severe combined immunodeficency (SCID).

- Lymphopenia may be a good marker of SCID.

- Absent or abnormal thymic shadow may be an indicator of an immunodeficiency.

CanMeds Competency: Medical Expert

Pretest

- What characteristics of a respiratory tract infection are concerning for an underlying immunodeficiency?

- Can lymphopenia be a useful marker in screening patients for an underlying immunodeficiency?

Case 1

\section{CASE PRESENTATION}

A two-month-old male infant of nonconsanguineous Mexican Mennonite descent presented to a rural hospital for respiratory distress treated with nebulized budesonide (Pulmicort, AstraZeneca, Sweden) and salbutamol. He was discharged after two days without any home oxygen requirement. He was readmitted two months later with respiratory distress and failure to thrive. A chest radiograph at that time revealed bilateral perihilar densities that were treated with cefotaxime. He had a history of persistent oral candidiasis unresponsive to nystatin and diarrhea starting within the first few weeks of life. There was no
La présentation respiratoire du déficit immunitaire combiné sévère chez deux enfants mennonites dans un centre de soins tertiaires fait ressortir l'importance de dépister cette urgence pédiatrique

Le déficit immunitaire combiné sévère (DICS) est considéré comme une urgence pédiatrique, la détresse pédiatrique en étant le symptôme révélateur le plus courant. Les auteurs présentent deux cas de DICS chez des enfants de moins de quatre mois ayant une détresse respiratoire dans un centre de soins tertiaires en raison d'une mutation homozygote du gène $\mathrm{CD} 3$ delta décrite récemment, qu'on observe seulement dans la population mennonite mexicaine. L'absence de réponse à un antibiotique à large spectre a suscité des examens afin de diagnostiquer une DICS potentielle. Le liquide de lavage broncho-alvéolaire des deux patients a mis en évidence le Pneumocystis jiroveci, et la cytométrie de flux a révélé l'absence de lymphocytes $\mathrm{T}$. On croit que le gène $\mathrm{CD} 3$ delta est important pour la différenciation et la maturation des lymphocytes $\mathrm{T}$. Le présent article rappelle aux pédiatres et aux pneumologues pédiatres que le secret du diagnostic de DICS consiste à présenter un fort indice de présomption lorsque les patients répondent peu aux thérapies habituelles.

family history of immunodeficiency or early infantile deaths, and the patient had two healthy older siblings.

Bloodwork revealed a hemoglobin level of $101 \mathrm{~g} / \mathrm{L}$, a white blood cell count of $10.8 \times 10^{9} / \mathrm{L}$, neutrophils $5.06 \times 10^{9} / \mathrm{L}$, lymphocytes $3.76 \times 10^{9} / \mathrm{L}$ and platelet count of $480 \times 10^{9} / \mathrm{L}$. A nasopharyngeal swab was positive for entero/rhino/metapneumovirus. Urine, stool and blood cultures were negative.

He was transferred to a tertiary pediatric centre (Alberta Children's Hospital, Calgary, Alberta) for further investigations for his persistent respiratory distress. On initial assessment, his weight was $<3$ rd percentile and his length was at the 25 th percentile. He was afebrile, with an arterial oxygen saturation $\left(\mathrm{SpO}_{2}\right)$ of $93 \%$ on $0.25 \mathrm{~L} / \mathrm{min}$ of oxygen. Significant examination findings included tachypnea (respiratory rate 50 to 60 breaths/min), with tracheal tug and intercostal indrawing. He had decreased air entry to the bases, oral candidiasis and small bilateral cervical lymph nodes, but the tonsils were not appreciated.

Chest radiographs on admission revealed bilateral perihilar infiltrates and an absent thymic shadow (Figure 1). On review of previous films, the thymic shadow was also absent. A computed tomography scan confirmed the absence of a thymus (Figure 2).

Because of his worsening clinical status, a bronchoscopy with bronchoalveolar lavage was performed, with Pneumocystis jiroveci (PJP) noted; treatment with high-dose trimethoprim/sulfamethoxazole (Septra, GlaxoSmithKline, USA) was initiated.

An immunodeficiency workup revealed an undetectable immunoglobulin (Ig) A level $<0.04 \mathrm{~g} / \mathrm{L}$ (normal range $0.05 \mathrm{~g} / \mathrm{L}$ to $1.20 \mathrm{~g} / \mathrm{L}$ ), a very low IgG level of $0.99 \mathrm{~g} / \mathrm{L}$ (normal range $2.80 \mathrm{~g} / \mathrm{L}$ to $16.0 \mathrm{~g} / \mathrm{L}$ ) and

${ }^{1}$ Department of Pediatrics; ${ }^{2}$ Section of Allergy and Immunology; ${ }^{3}$ Department of Diagnostic Imaging; ${ }^{4}$ Section of Respiratory Medicine, Alberta Children's Hospital, Calgary, Alberta

Correspondence and reprints: Dr Mary E Noseworthy, Section of Respiratory Medicine, Alberta Children's Hospital, 2888 Shaganappi Trail Northwest, Calgary, Alberta T3B 6A8. Telephone 403-955-7503, e-mail mary.noseworthy@albertahealthservices.ca 


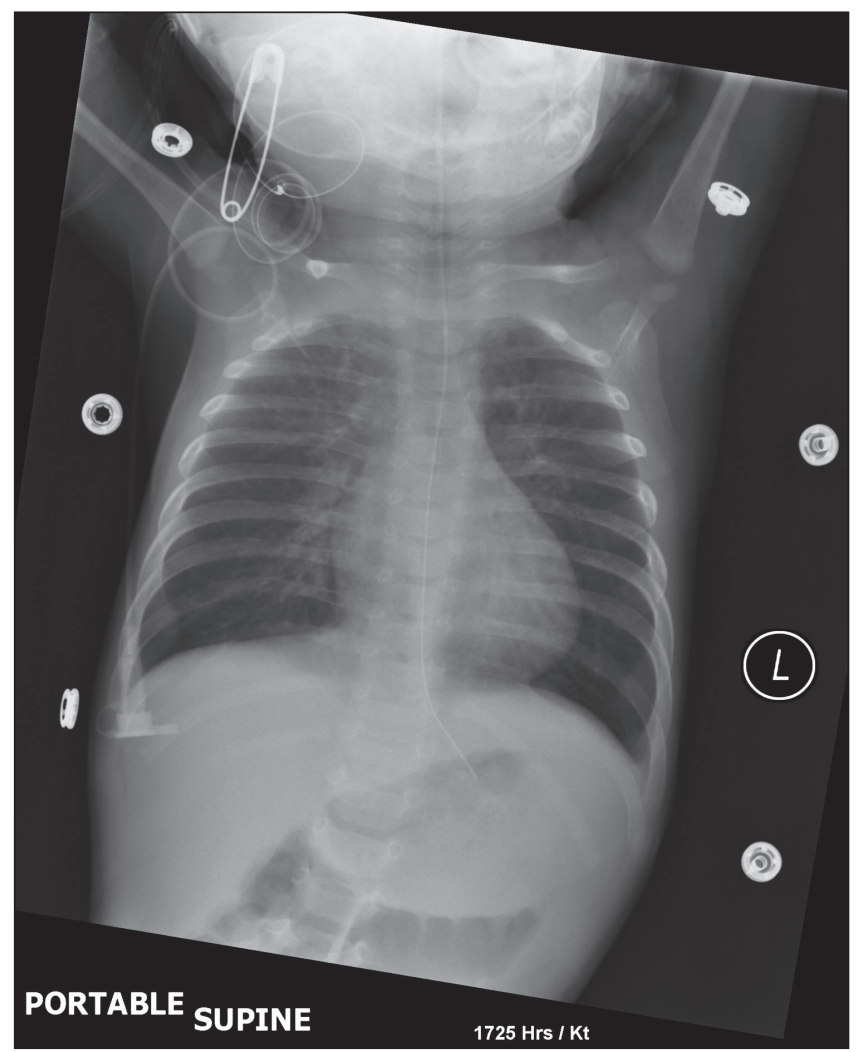

Figure 1) Chest radiograph of the patient described in case 1 on presentation revealing bilateral perihilar infiltrates without a thymic shadow

normal IgM 0.19 g/L (normal range $0.14 \mathrm{~g} / \mathrm{L}$ to $1.40 \mathrm{~g} / \mathrm{L}$ ). Flow cytometry showed absent $\mathrm{T}$ cells with normal B cell and natural killer (NK) cell populations. HIV polymerase chain reaction testing was negative and, therefore, a diagnosis of $\mathrm{T}^{-} \mathrm{B}^{+} \mathrm{NK}^{+}$SCID was presumed. This was further confirmed when genetic testing found a homozygous mutation in the CD3 delta gene.

\section{Case 2}

A two-month-old boy of nonconsanguineous Mexican Mennonite descent was seen for an apneic spell, cyanosis and increased work of breathing. He was diagnosed with respiratory syncytial virus bronchiolitis, admitted for seven days and treated with nebulized epinephrine. He was discharged without any home oxygen requirements. Two weeks later, he returned with fever, cough and increased work of breathing. The chest radiograph was consistent with right upper lobe and left lower lobe (LLL) pneumonia. He was readmitted and treated with ceftriaxone. On day 7, vancomycin was added and he was then transferred to the centre for persistent respiratory distress. Family history revealed eight infant deaths from 'fungal infections'. None of these infants had received a formal diagnosis of SCID. The parents were also from the same Mexican Mennonite colony. This particular patient was an only child.

On presentation, he was at the 50th to 75 th percentile for weight and 90 th percentile for length. He was afebrile, with an $\mathrm{SpO}_{2}$ of $96 \%$ on $1 \mathrm{~L} / \mathrm{min}$ of oxygen. Significant examination findings included tachypnea (respiratory rate of 30 to 40 breaths/min) with increased work of breathing (nasal flaring, intercostals and supracostal indrawing). Air entry was decreased and crackles were noted in the upper lobes bilaterally. Small lymph nodes in the cervical region noted but tonsils were absent.

Bloodwork showed hemoglobin level of $88 \mathrm{~g} / \mathrm{L}$, a white blood cell count of $5.2 \times 10^{9} / \mathrm{L}$, neutrophils $5 \times 10^{9} / \mathrm{L}$, lymphocytes $1.2 \times 10^{9} / \mathrm{L}$ and a platelet count of $480 \times 10^{9} / \mathrm{L}$. Chest radiograph showed right upper lobe consolidation and a smaller than expected thymic shadow (Figure 3).
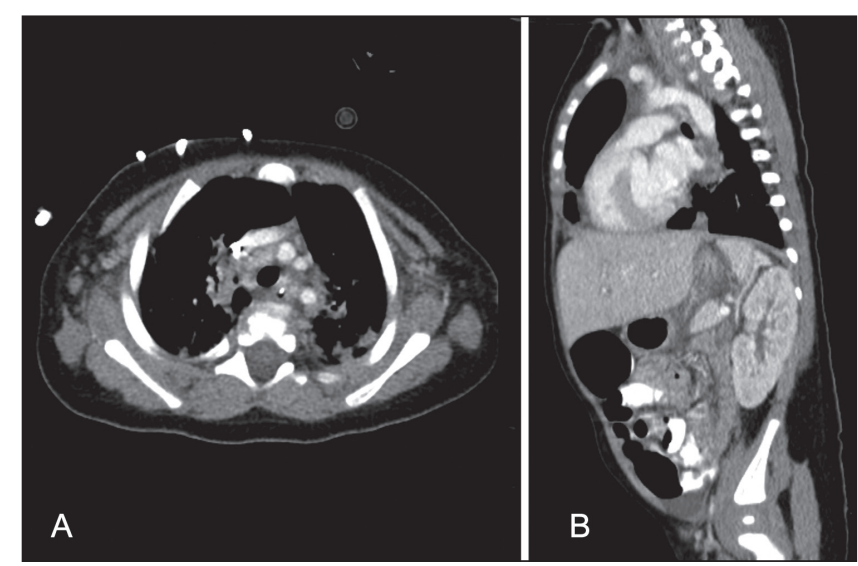

Figure 2) Computed tomography of the chest of the patient described in case 1, revealing absent thymic tissue in the anterior mediastinum. A Axial section. B Sagittal section
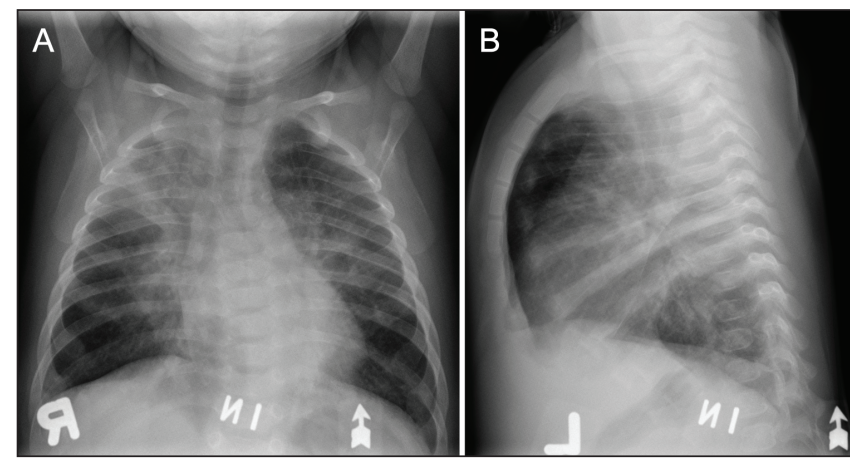

Figure 3) Chest radiograph of the patient described in case 2 on presentation, revealing a right upper lobe consolidation and a smaller than expected thymic shadow

Bronchoalveolar lavage was performed on day 3 of admission because of worsening clinical status and was positive for PJP. The patient was started on high-dose trimethprim-sulfamethoxazole.

In light of the PJP, an immunodeficiency evaluation revealed an undetectable IgA level of $<0.05 \mathrm{~g} / \mathrm{L}$ (normal range $0.05 \mathrm{~g} / \mathrm{L}$ to $1.20 \mathrm{~g} / \mathrm{L}$ ), low IgG of $2.43 \mathrm{~g} / \mathrm{L}$ (normal range $2.80 \mathrm{~g} / \mathrm{L}$ to $16.00 \mathrm{~g} / \mathrm{L}$ ) and normal IgM of $0.51 \mathrm{~g} / \mathrm{L}$ (normal range $0.14 \mathrm{~g} / \mathrm{L}$ to $1.40 \mathrm{~g} / \mathrm{L}$ ). Flow cytometry revealed the absence of $\mathrm{T}$ cells, with a normal number of $\mathrm{B}$ cell and $\mathrm{NK}$ cell populations. Genetic testing found a homozygous mutation in the CD3 delta gene that confirmed the etiology of SCID in this patient.

\section{DISCUSSION}

SCID is a group of genetically distinct entities that lead to defective T cell development affecting both adaptive and humoral immunity. More than 10 gene mutations involving cytokine receptors, antigen receptors, intracellular signalling and $\mathrm{T}$ cell apoptosis have been identified to be causative for SCID (1).

With an estimated incidence of one in 50,000 to 100,000 live births, the most common manifestations of SCID are chronic diarrhea and pneumonitis $(1,2)$. Other frequent features include failure to thrive, oral candidiasis that responds poorly to topical antifungals, lack of palpable lymphatic tissue and absent thymic shadow on chest radiograph.

The key to diagnosis is having a high index of suspicion for SCID in infants with chronic, recurrent infections that are not responsive to conventional treatment. A positive family history of infantile death is also an alarming indicator that an evaluation should be performed. In case 2, the family history of numerous infantile deaths was overwhelming. In ideal circumstances, a family with such a history could have undergone prenatal evaluation and testing at birth, with immediate isolation of the newborn if SCID was suspected. 
The initial evaluation of a patient with SCID involves a complete blood count. Lymphopenia $<2000$ lymphocytes $/ \mu \mathrm{L}$ is common; however, up to $20 \%$ to $30 \%$ of SCID patients may have a normal lymphocyte count (3). Flow cytometry is used to determine the composition of the lymphocyte subset, determining the individual number of T cells, B cells and NK cells, which is helpful to decipher the genetic etiology of SCID.

For example, our cases demonstrated a total lack of T cell development but a preservation of $\mathrm{B}$ and $\mathrm{NK}$ cell numbers, which significantly narrowed the potential genetic causes that required investigation. The invasive procedure of a thymic biopsy can be used to demonstrate the dysplastic nature of a SCID thymus. This was particularly performed in the past when less was known about the molecular basis of SCID and patients often received a bone marrow transplant with a phenotype of SCID but not necessarily a genotype. Thankfully, this procedure can now often be replaced with the real-time genetic analysis of thymic output known as TREC. TREC are the byproduct of efficient and comprehensive DNA rearrangement of $\mathrm{T}$ cell receptors when new $\mathrm{T}$ cells are maturing in the thymus. Lack of TREC suggests that the thymus is not producing the expansive repertoire of $\mathrm{T}$ cell receptors needed for a mature and functional immune system. Patients with SCID typically have low to absent TREC, making it a more sensitive and specific marker than the overall lymphocyte count of a complete blood count for detecting SCID. As a result, this technology has been proposed as the best way to perform neonatal screening for SCID (4).

With the recent advent of TREC, it is now possible to screen for SCID using dried blood spots (4). As a result, newborn screening (NBS) for SCID has been an increasingly debated topic in the literature. Several American states, such as Wisconsin, Massachusetts and California, have trialled NBS programs based on TREC. From the success of these programs, the Secretary of the Department of Health and Human Services approved the recommendation to add SCID to NBS protocols throughout the United States (5) in 2010. Although beyond the scope of the present report, there certainly are barriers to widespread implementation of NBS for SCID such as significant initial laboratory set-up costs, lack of familiarity with SCID among primary care physicians, an inadequate number of immunologists in some areas and the lack of the ability to perform hematopoietic stem cell transplant (HSCT) in some centres (4).

The current literature almost exclusively describes the status of NBS for SCID in the United States. However, with the recent implementation of NBS for SCID in Ontario in 2013, it will be interesting to follow the outcomes of this novel Canadian program.

SCID is a pediatric emergency because infection-induced organ damage - particularly to the lungs - worsens outcome (6). SCID patients who underwent HSCT in the neonatal period had much higher levels of $\mathrm{T}$ cell reconstitution, thymic output and less mortality than those transplanted after the neonatal period (1). Mortality and morbidity increase with delayed diagnosis due to an increased burden of infection. Survival rates decline from infection with delayed diagnosis. A recent study over a 28.3-year period demonstrated improved survival (94\%) if the transplant was received within 3.5 months compared with 69\% survival if transplanted after this age (1).

With HSCT enabling the strong possibility of cure and a normal life for affected children, the stark differences in outcome and healthcare costs resulting from delays in diagnosis are the main impetus for expediting NBS with TREC analysis.

Both of these Mennonite cases presented with a homozygous mutation in the CD3 delta gene, which has only been relatively recently described (7). This gene is important for downstream signalling, differentiation and maturation of early $\mathrm{T}$ cells (8). This mutation results in a $\mathrm{T}$ cell-negative, B cell-positive, NK cell-positive $\left(\mathrm{T}^{-} \mathrm{B}^{+} \mathrm{NK}^{+}\right)$SCID, which is frequently associated with a small dysplastic thymus (7).

\section{Case 1}

The patient underwent a sibling-matched HSCT at 7.4 months of age, and developed complications of veno-occlusive disease and hypertension. One month post-transplant, he deteriorated with an aggressive human metapneumovirus infection and died at 9.4 months of age.

\section{Case 2}

The patient's siblings were not a match for his bone marrow transplant. His respiratory status continued to deteriorate, with respiratory syncytial virus and coronavirus infection. The patient died at 3.4 months of age.

\section{SUMMARY}

Respiratory distress is a presenting feature in the majority of infants diagnosed with SCID. The key to rapid diagnosis is a high index of suspicion. Lymphopenia (<2000 lymphocytes $/ \mu \mathrm{L})$ can be helpful, but $20 \%$ to $30 \%$ of SCID patients may have a normal lymphocyte counts. A timely diagnosis with early HSCT leads to best outcomes. The physician should consider SCID in a patient with failure to thrive, recurrent and resistant respiratory infections, family history of early infantile deaths, or with in patients with absent or reduced thymic shadow chest radiograph.

\section{Post-test}

- What characteristics of a respiratory tract infection are concerning for an underlying immunodeficiency?

These include any respiratory tract infection with failure to thrive, chronic diarrhea, resistant thrush, with absent or reduced thymic shadow chest radiograph, as well any recurrent and resistant respiratory infections despite intervention with appropriate therapies.

- Can lymphopenia be a useful marker in screening patients for an underlying immunodeficiency?

Yes, a low lymphocyte count $(<2000 / \mu \mathrm{L})$ can be helpful as well in making the diagnosis. However, as many as $20 \%$ of patients with SCID can have a normal lymphocyte count.

AUTHOR CONTRIBUTIONS: MN was the primary respirologist involved with both cases. FK was one of the immunologists in both cases. $\mathrm{MN}$ and FK were vital in the conception of this case report. SL performed the chart review for both patients and wrote the case report. SH reviewed the diagnostic imaging for both cases, prepared the images for submissions and provided information regarding imaging in immunocompromised patients. MN, FK and $\mathrm{SH}$ were heavily involved with editing and revising the case report written by SL.

\section{REFERENCES}

1. Myers LA, Patel DD, Puck JM, Buckley RH. Hematopoietic stem cell transplantation for severe combined immunodeficiency in the neonatal period leads to superior thymic output and improved survival. Blood 2002;99:872-8.

2. Lipstein EA, Vorono S, Browning MF, et al. Systematic evidence review of newborn screening and treatment of severe combined immunodeficiency. Pediatrics 2010;125:e1226-35.

3. Hague RA, Rassam S, Morgan G, Cant AJ. Early diagnosis of severe combined immunodeficiency syndrome. Arch Dis Child 1994;70:260-3.

4. Buckley RH. The long quest for neonatal screening for severe combined immunodeficiency. J Allergy Clin Immunol 2012;129:597-604.

5. Accetta Pedersen DJ, Verbsky J, Routes JM. Screening newborns for primary T-cell immunodeficiencies: Consensus and controversy. Expert Rev Clin Immunol 2011;7:761-8.

6. Fischer A, Landais P, Friedrich W, et al. European experience of bone-marrow transplantation for severe combined immunodeficiency. Lancet 1990;336:850-4.

7. Dadi HK, Simon AJ, Roifman CM. Effect of CD3delta deficiency on maturation of alpha/beta and gamma/delta T-cell lineages in severe combined immunodeficiency. N Engl J Med 2003;349:1821-8.

8. Fischer A, de Saint Basile G, Le Deist F. CD3 deficiencies. Curr Opin Allergy Clin Immunol 2005;5:491-5. 


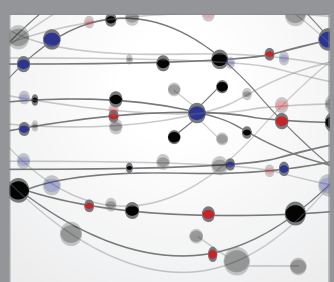

The Scientific World Journal
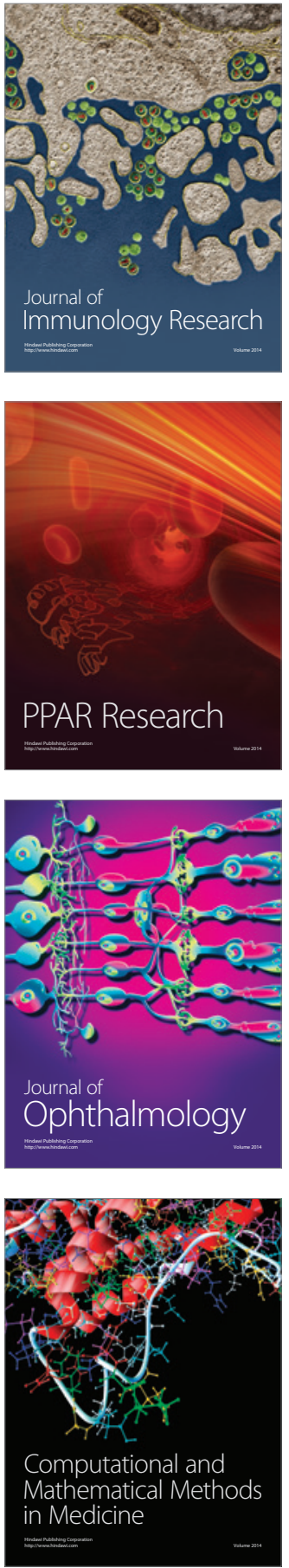

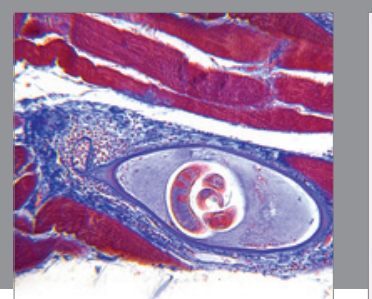

Gastroenterology Research and Practice

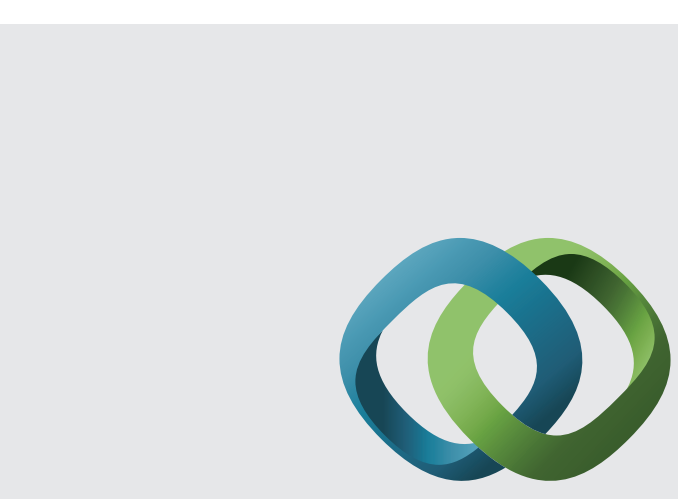

\section{Hindawi}

Submit your manuscripts at

http://www.hindawi.com

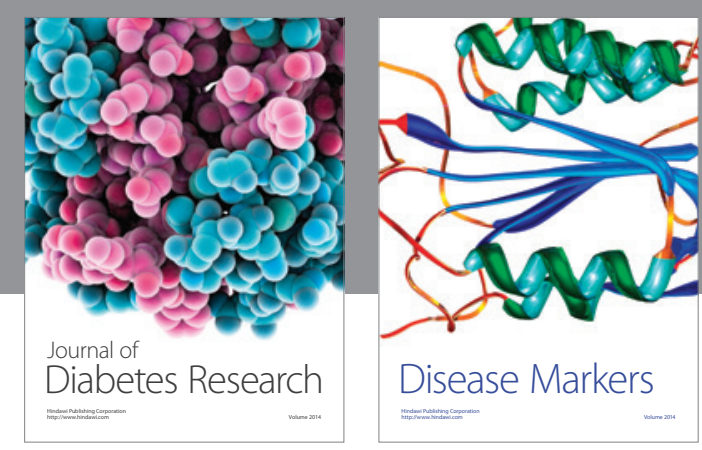

Disease Markers
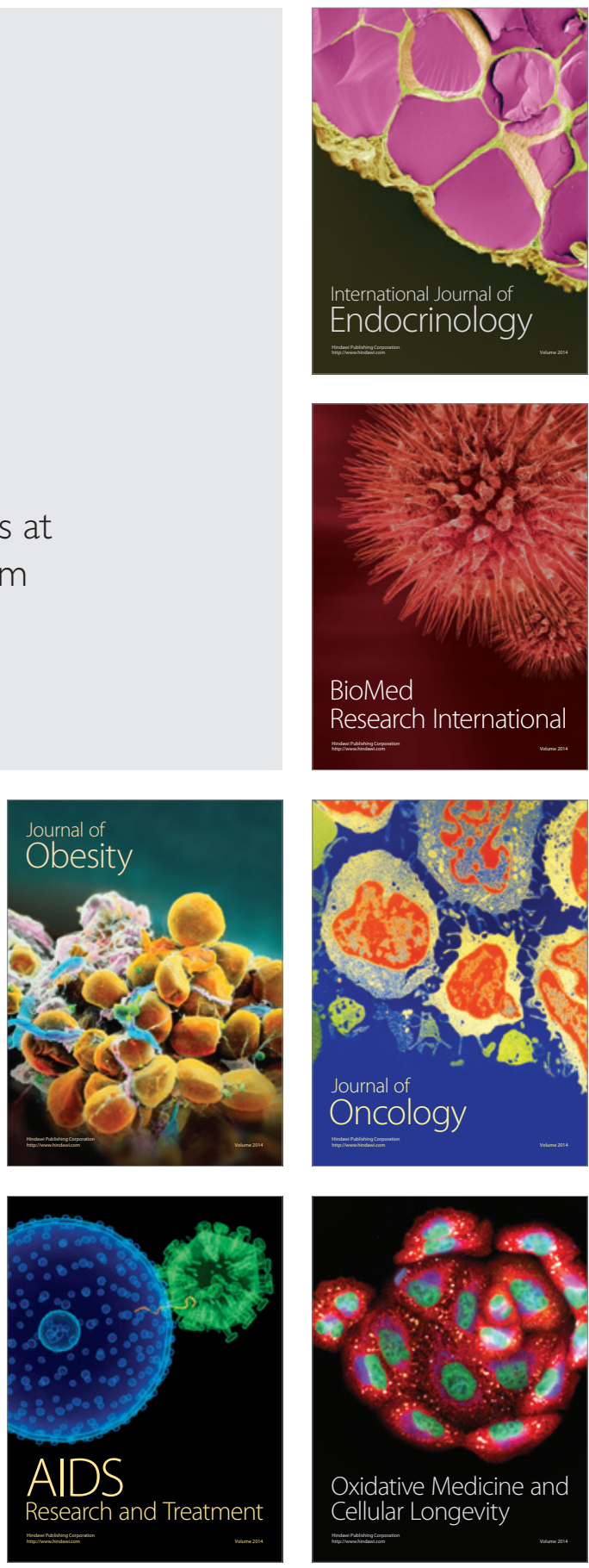